\title{
Integrated syphilis/HIV screening in China: a qualitative analysis
}

\author{
Joseph D Tucker ${ }^{1 *}$, Li-Gang Yang ${ }^{2}$, Zheng-Jun Zhu ${ }^{3}$, Bin Yang ${ }^{2}$, Yue-Pin Yin ${ }^{4}$, Myron S Cohen ${ }^{5}$, Xiang-Sheng Chen ${ }^{4}$
}

\begin{abstract}
Background: The last decade has seen enormous advances in HIV treatment and care, but how to implement scaled up HIV testing, prevention, and treatment in low-income areas still presents a formidable public health challenge. South China faces expanding syphilis and sexually transmitted HIV epidemics, but health systems characteristics important for scaling up syphilis and HIV testing have not been defined.
\end{abstract}

Methods: A purposive sample to ensure public, private, and public-private hybrid STI clinic inclusion was selected in a South China city. Eight key informant interviews were conducted with the STI clinic manager, followed by eight focus group discussions with physicians. Data collection relied on a semi-structured format that included questions in each of the following domains: 1) clinical facilities; 2) laboratory capacity with a focus on syphilis/HIV diagnosis; 3) clinic personnel; 4) physical space with a focus on locations to disclose confidential results; 5) financial support.

Results: Public STI clinics had free syphilis testing/treatment and laboratory facilities to perform essential syphilis and HIV tests. However, despite serving a large number of STI patients, private STI clinics lacked nontreponemal syphilis testing, HIV testing, and had fewer connections to the public health infrastructure. Formally trained assistant physicians were 2.5 times as common as physicians at STI clinics. Only one of the 8 sites had onsite voluntary counseling and testing (VCT) services available.

Conclusion: These STI case studies reveal the potential for expanding integrated syphilis/HIV services at public STI clinics in China. More health services research is needed to guide scale-up of syphilis/HIV testing in China.

\section{Background}

The last decade has seen enormous advances in HIV treatment and care, but how to implement scaled up HIV testing, prevention, and treatment in low-income areas still presents a formidable public health challenge [1]. Approximately $90 \%$ of new syphilis cases globally are in low-income areas where sexually transmitted HIV is also a major public health problem [2]. Syphilis increases the risk of HIV acquisition [3] and transmission $[4,5]$ and patients with either STI frequently attend the same STI clinics. In 2008, China had 278,215 officially reported syphilis cases, a threefold rise in the number of reported cases compared to 2004 and a tenfold increase over the last decade [6,7]. Effective scaleup of integrated syphilis/HIV services demands scalable, high quality clinical STI services.

\footnotetext{
* Correspondence: jtucker4@partners.org

${ }^{1}$ Division of Infectious Diseases, Massachusetts General Hospital, Boston, USA
}

While the need for integrated syphilis/HIV testing at STI clinics in China has increased, health market reforms in China have limited the capacity of local STI clinics to meet the growing demand for syphilis/HIV screening services [8]. The army of barefoot doctors in the context of a broad reaching anti-epidemic disease station system subsidized by the state has largely been replaced by a fee-for-service STI clinic system. Although China has a nationwide network of standardized public STI clinics, this established infrastructure has been bypassed by large numbers of STI patients who seek care at private clinics [9-14]. The literature on private STI clinics, including syphilis/HIV testing capacity and human resources, is scant [15].

In order to understand the scalability of providing integrated syphilis/HIV services at STI clinics in China, we conducted operational STI clinic research in Guangdong Province, a rapidly developing region with increasing syphilis burden in South China (Figure 1). Public 


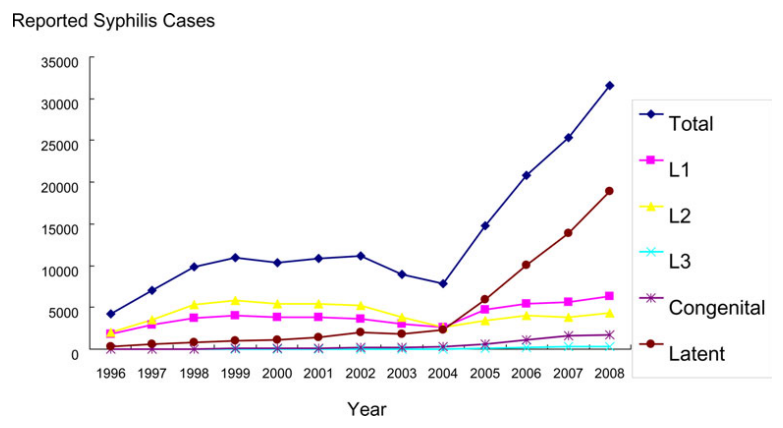

Figure 1 Reported syphilis cases in Guangdong Province, China, from 1996-2008. L1 - primary syphilis; L2 - secondary syphilis; L3 - tertiary syphilis. Source: Guangdong Provincial STI/ Leprosy Conference 2009, Jiangmen City, China.

STI clinics were selected instead of other clinical facilities that might provide similar syphilis/HIV services (obstetrics and gynecology, urology, family planning, etc) because STI clinics have a higher burden of STIs [12] and a national infrastructure that reaches to the township level. These case studies analyzed the clinical, laboratory, and human capacity at various types of STI clinics in China to inform implementation of integrated syphilis/HIV testing efforts and guide scale-up policy. This research employed qualitative methods because litthe is known about the operational characteristics of STI clinics, especially non-public clinics, in China.

\section{Methods}

Jiangmen City is located in the southcentral region of Guangdong Province, west of the Pearl River Delta. Adjacent to Zhongshan in the east and Foshan in the north, the city faces southward to the South Sea and neighbors Hong Kong and Macau. It is accessible to Hong Kong via a two-hour ferry ride, and has major highways that connect to the provincial capital, Guangzhou, and Hong Kong. Jiangmen has a total population of 3.9 million, and consists of 3 districts and 4 countylevel cities.

A qualitative approach was used because of the limited data available to structure quantitative data collection [12] and the complexity of social factors in relation to operational clinic characteristics [16]. The formative data from this qualitative study then informed a larger quantitative analysis of syphilis/HIV testing at STI clinics. Interviews with STI clinic managers were chosen since managers have first-hand knowledge of many operational variables unknown to individual physicians (e.g., laboratory grade). Focus groups were also used with physicians because of convenience and the limited sensitive material, consistent with other studies focused on operational characteristics of health care in China $[17,18]$. A purposive technique was used to select a convenience sample of STI clinics in Jiangmen City in order to ensure a range of clinic types, including public, private, and public-private hybrid STI clinics. A total of eight STI clinics were chosen, and each of the clinics was contacted by telephone to review study eligibility.

An interview guide was assembled based on the following core domains related to delivery of integrated syphilis/HIV testing: a) clinical facilities (e.g., daily number of patients) b) laboratory capacity with a focus on syphilis/HIV testing (tests available onsite and referred away); c) clinic personnel; d) physical space with a focus on locations to disclose confidential results; e) financial support. Domains were chosen based on their relevance to implementation of syphilis/HIV testing services $[19,20]$. Survey items used previously in China to evaluate HIV testing among physicians [21] were expanded to include syphilis testing. All survey items were pretested with physicians in the public health bureau prior to data collection. Standardized Chinese public health grades were used to classify laboratory capacity, ranging from 1 (most basic, able to perform rapid test) to 3 (most advanced, able to perform HIV CD4 counts). Key informant interviews with STI clinic managers were conducted in a private, enclosed room away from clinical services. The interviews were conducted one-on-one with a trained research assistant in the local language, and notes were recorded by two research assistants. After key informant interviews, STI clinic managers gave a tour of the physical facilities with a focus on individual clinic rooms and clinic laboratory facilities. STI clinic manager meetings preceded the focus groups and this ordering was used to contextualize and further refine appropriate questions for focus group discussions. Focus group discussions included clinicians, laboratory technicians, and nurses. All research notes were transcribed and translated into English, and open-ended questions were coded by themes and analyzed by two independent research assistants. Conflicts in the data were resolved by the lead investigator and a summary data were produced for each of the eight study sites based on the results of coding. This study was approved by the National STD Center IRB, the UNC IRB, and the Partners Human Research Committee.

\section{Results}

Among the eight STI clinics included in this study, three were independent public clinics, three were general hospital-associated, one was completely private, and one was a public/private hybrid (Table 1). The three independent STI clinics were administratively underneath the national STI control center within the Chinese Centers for Disease Control while the public general hospital STI clinics were administratively within the general hospital infrastructure. These two systems both 
Table 1 Operational characteristics of eight STI clinics in South China

\begin{tabular}{|c|c|c|c|c|c|c|c|c|}
\hline$\#$ & Type & $\begin{array}{l}\text { STI visits } \\
\text { per year }\end{array}$ & $\begin{array}{l}\text { Total } \\
\text { personnel }\end{array}$ & $\begin{array}{l}\text { MD'/assistant } \\
\text { MD/RN }\end{array}$ & $\begin{array}{l}\text { Certified } \\
\text { Laboratory }^{2}\end{array}$ & Hours & CDC link & $\begin{array}{l}\text { Gov't } \\
\text { support }\end{array}$ \\
\hline 1 & Public independent clinic & $\sim 3,900$ & 60 & $3 / 14 / 22$ & Grade 2 & $8 a m-6: 30 p m$ & Yes & Yes \\
\hline 2 & Public independent clinic & $\sim 940-1,560$ & 20 & $0 / 5 / 6$ & Informal & $8: 00 a m-6: 30 p m$ & Yes & Yes \\
\hline 3 & Public independent clinic & $\sim 1450$ & $30-35$ & $2 / 5 / 5$ & Grade 2 & $9: 00 a m-6: 00$ pm & Yes & Yes \\
\hline 4 & Public general hospital & $\sim 610-930$ & 4 & $3 / 0 / 1$ & Grade 3 & $8: 00 a m-5: 30 p m$ & Yes & Yes \\
\hline 5 & Public general hospital & $\sim 260-520$ & 2 & $0 / 2 / 1$ & Grade 3 & $8: 00 a m-5: 30$ pm & No & Yes \\
\hline 6 & Public general hospital & $\sim 5720-8580$ & 6 & $2 / 2 / 1$ & Grade 3 & $8: 00 a m-5: 00$ pm & Yes & Yes \\
\hline 7 & Private & $\sim 1090-1820$ & 35 & $5 / 6 / 15$ & Informal & 24 hours & No & No \\
\hline 8 & Public/private ${ }^{3}$ & $\sim 10,600$ & 100 & $10 / 30 / 35$ & Informal & 8:00 am - 9:30 pm & $\begin{array}{l}\text { Refer patients to } \\
\text { CDC ID }\end{array}$ & Yes $^{3}$ \\
\hline
\end{tabular}

${ }^{1}$ Definitions of health care providers used standard Chinese medical classifications [31].

${ }^{2}$ China's system of laboratory specifications has three tiers - grade 3 (highest level), grade 2 (mid level), grade 1 (lowest level).

${ }^{3}$ This is a private clinic that operates with limited government support in direct relationship to the amount of money that the clinic pays.

report syphilis and HIV cases to the local public health authorities and have similar clinical responsibilities, although there was limited communication, shared training, or other joint activities. Seven out of eight of the clinics perceived private clinics as the main competitor in terms of providing local STI services. There were large variations in the estimated nonunique STI patients per year (Table 1). Neither of the private STI clinics had formal laboratories that could be rated using established laboratory certification criteria, but five of six public clinics had laboratories that met Chinese certification criteria (Table 1). All clinics reported short patient waiting times, generally less than 30 minutes to be evaluated by a physician.

Our data revealed substantial variation in medical training backgrounds. Licensed physicians in China have at least a bachelor's degree in medicine, pass a licensure examination, and complete one year of supervised internship at a clinic or preventive health institution. Licensed assistant physicians must have at least two years of medical training at a technical school following high school, pass a licensure examination, and complete one year of supervised internship at a clinic or preventive health institution. Nurses must have at least two years of training following high school, but no internship or examination is required. Across all eight sites, $28 \%$ of the STI clinicians were licensed physicians and $72 \%$ of STI clinicians were licensed assistant physicians, representing a 2.5 -fold difference. The total number of nurses at all clinics (86) was similar to the number of physicians (89).

Rapid treponemal syphilis testing was available in both the central public STI clinics and private clinics, but supported by different payment mechanisms (Table 2). The central public clinics were supported by a World Health Organization Sexually Transmitted Diseases Initiative to pay for syphilis rapid testing while the two private clinics charged patients for rapid syphilis testing.
The turnaround times reported for RPR tests were quite minimal, generally less than one day. Seven out of eight STI clinics had private rooms for the patient-physician encounter, but one of the general hospital-associated clinics had shared rooms for clinical STI evaluation.

Clinical STI service funding varied substantially according to clinic type. Public and hybrid STI clinics received direct support from the government and patient fees while the cost of private clinics is supported entirely by patient fees. Relationships with pharmaceutical representatives ranged from an explicit policy of no pharmaceutical representatives in the clinical area to pharmaceutical representatives in the same room as the physician and patient during the clinical encounter. Information on how ordering tests affected physician salaries was incomplete, but one private staff physician reported that there were direct financial incentives to order tests. This STI testing incentive did not apply to "free" tests provided by the STI clinic since these did not impact the clinic revenue or their salary.

\section{Discussion}

This study provides the first English language operational research on STI clinics in China, one of the key factors involved in scaling up high quality syphilis/HIV services. The large number of assistant physicians and nurses in STI clinics at both public and private STI clinics is important since training background has been shown to be associated with HIV stigma in China [22]. Inadequate HIV knowledge and high levels of HIV stigma have been observed among nurses and nursing students in China [22-24].

The finding that public STI clinics have greater laboratory capacity $[25,26]$, more trained personnel [27], and more clear reporting to the public health infrastructure [28] has been observed outside of China. The correlation between STI physician salaries and revenues generated from testing has also been described 
Table 2 HIV testing, syphilis testing, and related public health capacity at 8 STI clinics in South China

\begin{tabular}{|c|c|c|c|c|c|c|c|c|}
\hline$\overline{\#}$ & $\begin{array}{l}\text { Syphilis Nontreponem } \\
\text { Test/price/turnaround time }\end{array}$ & $\begin{array}{l}\text { Syphilis } \\
\text { Treponemal } \\
\text { Test }\end{array}$ & $\begin{array}{l}\text { Free syphilis } \\
\text { treatment }\end{array}$ & $\begin{array}{l}\text { HIV ELISA/price/ } \\
\text { turnaround time }\end{array}$ & $\begin{array}{l}\text { One-on- } \\
\text { one } \\
\text { rooms }\end{array}$ & Counseling & $\begin{array}{l}\text { Reporting to } \\
\text { official system }\end{array}$ & $\begin{array}{l}\text { Referral of HIV } \\
+ \text { to local CDC }\end{array}$ \\
\hline 1 & RPR/free/several hours & $\begin{array}{l}\text { Rapid test/ } \\
\text { free/minutes }\end{array}$ & Yes & Yes/\$9/same day & Yes & Free VCT & Yes & Yes \\
\hline 2 & RPR/free/several hours & $\begin{array}{l}\text { Rapid test/ } \\
\text { free/minutes }\end{array}$ & Yes & Yes/\$11/same day & Yes & None & Yes & Yes \\
\hline 3 & $\mathrm{RPR} / \$ 7 /$ several hours & $\begin{array}{l}\text { TPPA } \$ 5 / \\
\text { several hours }\end{array}$ & No & $\begin{array}{l}\text { Yes } / \$ 10 / \text { several } \\
\text { hours }\end{array}$ & Yes & None & Yes & Yes \\
\hline 4 & $\mathrm{RPR} / \$ 5 / 3$ days & $\begin{array}{l}\text { TPPA } / \$ 3 / 3 \\
\text { days }\end{array}$ & No & Yes $/ \$ 9 / 3$ days & No & None & Yes & Yes \\
\hline 5 & $\begin{array}{l}\text { RPR/TPPA combined } \$ 7 / \\
\text { several hours }\end{array}$ & No & Yes/\$9/hours & Yes & Yes & Yes & Yes & \\
\hline 6 & $\mathrm{RPR} / \$ 1.50 / 30$ minutes & $\begin{array}{l}\text { TPPA/\$10/ } \\
\text { hours }\end{array}$ & No & Yes/\$9/hours & Yes & None & Yes & Yes \\
\hline 7 & none & $\begin{array}{l}\text { Rapid test } / \$ 5 / \\
\text { few minutes }\end{array}$ & No & Yes $/ \$ 9 /$ minutes & Yes & None & No & Yes \\
\hline 8 & none & $\begin{array}{l}\text { TRUST/\$1.50/ } \\
\text { minutes }\end{array}$ & No & No & Yes & $\begin{array}{l}\text { Limited on } \\
\text { the phone }\end{array}$ & Yes & NA \\
\hline
\end{tabular}

Abbreviations - RPR, rapid plasma reagin; TPPA, Treponema Pallidum particle agglutination; Treponema Pallidum haemagglutination test. FTA-Abs, fluorescent treponemal antibody absorbed; VDRL, Venereal Disease Research Laboratory.

elsewhere. A US study found that privatized STI clinics were more likely to order tests for $C$. trachomatis and $N$. gonorrhoeae, both of which were reimbursed, rather than HIV and syphilis serologies [25]. This connection between physician salaries and diagnostic tests could have important implications for scaling up syphilis/HIV testing programs. The use of rapid syphilis and HIV tests at private clinics in China is surprising given that private clinicians are less likely to use rapid HIV tests in other contexts [28,29].

The substantial reported volume of private STI clinic patients is supported by several Chinese studies. Among those who reported getting treatment for an STD in the national 2000 census, $38 \%$ received treatment in private clinics and $25 \%$ never presented to a formal clinic [10]. One study found from Western China found that only $41 \%$ of STI patients went directly to a public clinic first, and where the patient lived was significantly related to their choice of clinic [11]. A study of STI/HIV care in Guangzhou and Shenzhen found that among 939 individuals, delays in receiving treatment among men were associated with seeking care at a private STI clinic [15]. In a study of health seeking behaviors from a large district of Beijing, only $2 \%$ of the sample sought care from a public STI clinic, while $61 \%$ sought care from other sources (private clinics, hospitals, and pharmacies)[30]. These studies confirm the importance of the private STI clinic in serving the needs of high risk populations in China.

This study has several limitations that merit discussion. Jiangmen City has greater economic resources than many cities in China, so the results cannot be generalized to all regions of China. In addition, each case study selected to investigate is part of a convenience sample that does not represent all STI clinic typologies. This limitation is perhaps most pronounced in the case of the private clinics where the illegal, underground nature of some private STI clinics makes identification of both clinics and a sampling unit challenging. Unlicensed physicians also provide STI services in China, but were not sampled in this study. In addition, accurately recording physician reported information about reimbursement and financial incentives can be a sensitive issue. Although this research used both one-on-one interviews and small group interviews, using longer indepth interviews may have uncovered more nuanced attitudes and behaviors related to financial incentives.

\section{Conclusions}

STI clinics in China are centrally important to responding to the related epidemics of syphilis and HIV infection. Our qualitative analysis of STI clinic physicians and managers in Guangdong Province found that public STI clinics had greater laboratory capacity, human resources, and connections to the public health system. The large number of assistant physicians at STI clinics in China can serve important roles in implementation of integrated syphilis and HIV testing. More health services research is needed about STI clinic systems in China to inform scale-up of effective syphilis/HIV testing programs.

\section{Acknowledgements}

We acknowledge the China Syphilis Working Group, the UNC Fogarty AIDS International Research and Training Program (NIH FIC D43 TW01039), the UNC Social Science Research on HIV/AIDS in China (NIH NICHD R24 
HD056670-01), the WHO Rapid Syphilis Test Project (WHO OD/TS-08-00088), the American Society for Tropical Medicine and Hygiene Postdoctoral Fellowship, the Harvard Initiative for Global Health, and the US NIH Fogarty Institute. The authors would like to thank the assistance of Lu He-Kun, Zhang Bao-Yuan, Huang Shu-Jie, Deng Wei-Jun, Shen Song-Ying, and Wang Cheng.

\section{Author details}

'Division of Infectious Diseases, Massachusetts General Hospital, Boston, USA. ${ }^{2}$ Guangdong Provincial Center for STI Control \& Prevention, Guangzhou, China. ${ }^{3}$ Jiangmen Skin Hospital, Jiangmen, China. ${ }^{4}$ National Center for STD Control, Nanjing, China. ${ }^{5}$ Institute for Global Health and Infectious Diseases, UNC Chapel Hill School of Medicine, Chapel Hill, USA.

\section{Authors' contributions}

All authors were involved in the conception and design of the study; JT, LY, $M C$, and XC analyzed and interpreted the data; all authors except MC helped draft the paper or substantially revised it. All the authors read and approved the final manuscript.

\section{Competing interests}

The authors declare that they have no competing interests.

Received: 29 August 2009

Accepted: 7 March 2010 Published: 7 March 2010

\section{References}

1. Coates TJ, Richter L, Caceres C: Behavioural strategies to reduce HIV transmission: how to make them work better. Lancet 2008, 372:669-684.

2. Peeling RW, Hook EW: The pathogenesis of syphilis: the Great Mimicker, revisited. J Pathol 2006, 208:224-232.

3. Reynolds SJ, Risbud AR, Shepherd ME, Rompalo AM, Ghate MV, Godbole SV, Joshi SN, Divekar AD, Gangakhedkar RR, Bollinger RC, Mehendale SM: High rates of syphilis among STI patients are contributing to the spread of HIV-1 in India. Sex Transm Infect 2006, 82:121-126.

4. Buchacz K, Patel P, Taylor M, Kerndt PR, Byers RH, Holmberg SD, Klausner JD: Syphilis increases HIV viral load and decreases CD4 cell counts in HIV-infected patients with new syphilis infections. Aids 2004, 18:2075-2079.

5. Powers KA, Poole C, Pettifor AE, Cohen MS: Rethinking the heterosexual infectivity of HIV-1: a systematic review and meta-analysis. Lancet Infect Dis 2008, 8:553-563.

6. Chen ZQ, Zhang GC, Gong XD, Lin C, Gao X, Liang GJ, Yue XL, Chen XS, Cohen MS: Syphilis in China: results of a national surveillance programme. Lancet 2007, 369:132-138.

7. CCDC/NCSTD: Sexually Transmitted Diseases Situational Briefing. Book Sexually Transmitted Diseases Situational Briefing (Editor ed.^eds.), City 2008, 222:2.

8. Blumenthal D, Hsiao W: Privatization and its discontents-the evolving Chinese health care system. N Engl J Med 2005, 353:1165-1170.

9. Parish WL, Laumann EO, Cohen MS, Pan S, Zheng H, Hoffman I, Wang T, $\mathrm{Ng} \mathrm{KH}$ : Population-based study of chlamydial infection in China: a hidden epidemic. Jama 2003, 289:1265-1273.

10. Ma JM, Liu N, Chen AP, Yang GH: [Study on knowledge, attitudes and behaviors regarding infectious diseases among Chinese people in 2002]. Zhonghua Liu Xing Bing Xue Za Zhi 2005, 26:389-393.

11. Lin ZC, Ou ZY, Ma YG: A study of health seeking behaviors among 489 STD patients detected by active surveillance. Chinese Journal of STD and AIDS Prevention and Control 2001, 7:273-277.

12. Zhao G, Detels R, Gu F, Li D, Li X, Li Y, Li K: The distribution of people seeking STD services in the various types of health care facilities in Chao Yang District, Beijing, China. Sex Transm Dis 2008, 35:65-67.

13. Zhao P, Yu H: [Study on sexual and drug use behaviors of high risk among sex workers in entertainment in establishments in Shanghai]. Zhonghua Liu Xing Bing Xue Za Zhi 2001, 22:341-343.

14. Guan J, Wu Z, Li L, Lin C, Rotheram-Borus MJ, Detels R, Hsieh J: Selfreported sexually transmitted disease symptoms and treatment-seeking behaviors in China. AIDS Patient Care STDS 2009, 23:443-448.

15. Choi KH, Zheng X, Zhou H, Chen W, Mandel J: Treatment delay and reliance on private physicians among patients with sexually transmitted diseases in China. Int J STD AIDS 1999, 10:309-315.
16. Yin RK: Case study research: design and methods Thousand Oaks, CA: Sage Publications 1994

17. Lim MK, Yang H, Zhang T, Zhou Z, Feng W, Chen Y: China's evolving health care market: how doctors feel and what they think. Health Policy 2004, 69:329-337.

18. Reynolds L, McKee M: Factors influencing antibiotic prescribing in China: an exploratory analysis. Health Policy 2009, 90:32-36.

19. Sanders D, Haines A: Implementation research is needed to achieve international health goals. PLOS Med 2006, 3:e186.

20. Madon T, Hofman KJ, Kupfer L, Glass Rl: Public health. Implementation science. Science 2007, 318:1728-1729.

21. Li L, Wu Z, Wu S, Lee SJ, Rotheram-Borus MJ, Detels R, Jia M, Sun S: Mandatory HIV testing in China: the perception of health-care providers. Int J STD AIDS 2007, 18:476-481.

22. Li L, Wu Z, Wu S, Zhaoc Y, Jia M, Yan Z: HIV-related stigma in health care settings: a survey of service providers in China. AIDS Patient Care STDS 2007, 21:753-762.

23. Li L, Lin C, Wu Z, Wu S, Rotheram-Borus MJ, Detels R, Jia M: Stigmatization and shame: consequences of caring for HIV/AIDS patients in China. AIDS Care 2007, 19:258-263.

24. Li Y, Scott CS, Li L: Chinese nursing students' HIV/AIDS knowledge, attitudes, and practice intentions. Appl Nurs Res 2008, 21:147-152.

25. Eubanks C, Lafferty WE, Kimball AM, MacCornack R, Kassler WJ: Privatization of STD services in Tacoma, Washington: a quality review. Sex Transm Dis 1999, 26:537-542.

26. Voeten HA, Otido JM, O'Hara HB, Kuperus AG, Borsboom GJ, NdinyaAchola JO, Bwayo JJ, Habbema JD: Quality of sexually transmitted disease case management in Nairobi, Kenya: a comparison among different types of healthcare facilities. Sex Transm Dis 2001, 28:633-642.

27. Mertens TE, Smith GD, Kantharaj K, Mugrditchian D, Radhakrishnan KM: Observations of sexually transmitted disease consultations in India. Public Health 1998, 112:123-128.

28. St Lawrence JS, Montano DE, Kasprzyk D, Phillips WR, Armstrong K, Leichliter JS: STD screening, testing, case reporting, and clinical and partner notification practices: a national survey of US physicians. Am J Public Health 2002, 92:1784-1788.

29. Bogart LM, Howerton D, Lange J, Becker K, Setodji CM, Asch SM: Scope of rapid HIV testing in private nonprofit urban community health settings in the United States. Am J Public Health 2008, 98:736-742.

30. Zhao G: Distribution of people seeking STD treatment in various types of treatment facilities in Chao Yang District, Beijing, China. University of California Los Angeles, Department of Epidemiology 2004.

31. Anand S, Fan VY, Zhang J, Zhang L, Ke Y, Dong Z, Chen LC: China's human resources for health: quantity, quality, and distribution. Lancet 2008 372:1774-81.

\section{Pre-publication history}

The pre-publication history for this paper can be accessed here:http://www. biomedcentral.com/1472-6963/10/58/prepub

doi:10.1186/1472-6963-10-58

Cite this article as: Tucker et al:: Integrated syphilis/HIV screening in

China: a qualitative analysis. BMC Health Services Research 2010 10:58.

\section{Submit your next manuscript to BioMed Central and take full advantage of:}

- Convenient online submission

- Thorough peer review

- No space constraints or color figure charges

- Immediate publication on acceptance

- Inclusion in PubMed, CAS, Scopus and Google Scholar

- Research which is freely available for redistribution 